\title{
Arrested apoptosis without nuclear fragmentation produced by efferent duct ligation in round spermatids and multinucleated giant cells of rat testis
}

\author{
E. Anton \\ Centro de Investigaciones en Reproducción, Facultad de Medicina, Universidad de Buenos Aires, \\ Paraguay 2155, P 10, 1121 Buenos Aires, Argentina
}

The apoptotic process evoked by efferent duct ligation in the testes of adult rats was followed for 10 days by differential staining for haematoxylin-eosin, periodic acid-Schiff and a modified trichrome technique in optical microscopy and by ultrastructural localization of acid phosphatase. Round spermatids showed the first effects of efferent duct ligation. At day 3 after ligation, annular clumps of chromatin with typical apoptotic characteristics appeared against the nuclear membrane of these cells. Afterwards, membranous structures and a wide separation between the two layers of the nuclear membrane were observed but nuclear fragmentation did not occur and apoptotic granules were not seen. Cytoplasmic components were also altered, and severely damaged organoids and empty vacuoles lacking acid phosphatase reaction were frequently seen. On day 2 after efferent duct ligation, multinucleated giant cells appeared, which displayed similar characteristics as spermatids and showed no acid phosphatase reaction. Although abnormal spermatids and multinucleated giant cells were surrounded by the cytoplasm of Sertoli cells, neither lysosomal acid phosphatase nor phagocytic activity was detected. It is concluded that efferent duct ligation specifically affects round immature spermatids eliciting a partial nuclear apoptotic response that is not accompanied by autophagic or heterophagic activity and without lysosomal participation in Sertoli cells.

\section{Introduction}

It is well established that efferent duct ligation, by blocking the flow of seminiferous fluid, results in changes in the epithelium and rapid atrophy of the seminiferous tubules (Smith, 1962; Anton, 1979; Vanha-Perttula and Arya, 1985; Tao et al., 2000).

Electron microscopical studies of rat testis after efferent duct ligation demonstrated that the seminiferous epithelium was selectively damaged, and that specific types of cells were affected. Thus, immature (round) spermatids degenerated, multinucleated giant cells rapidly appeared (Anton, 1979; Singh and Abe, 1987) and vacuolization of Sertoli cells proceeded (Anton, 1979).

The occurrence of spontaneous germ cell death in mammalian testes has been known for a long time, and it has been proposed that it serves as a control of germ cell population (De Rooij and Lok, 1987; Brinkworth et al., 1995; Matsui, 1998).

The phagocytic function of Sertoli cells with evident participation of lysosomes has been demonstrated by Dieter (1966) and Chemes (1986) in studies showing the disposal of degenerating germ cells and removal of residual cytoplasm from spermatids during normal sper-

Email: ebanton@hotmail.com miogenesis (Morales et al., 1985; Sakai and Yamashina, 1989).

There are two fundamental types of cell death: necrosis and apoptosis or programmed cell death. The two types have different morphological and biochemical characteristics and can occur simultaneously in the same tissue (Kerr et al., 1972; Walker et al., 1988; Majno and Joris, 1995; Kitanaka and Kuchino, 1999). Apoptosis can display peculiar characteristics in some tissues, and testicular apoptosis has quite different features from those displayed by somatic cells (Brinkworth et al., 1995). Moreover, evidence of incomplete apoptosis or a process combining features of apoptosis and necrosis in pathological processes affecting male germ cells has been reported (Weil et al., 1998; Sakkas et al., 1999; Tesarik et al., 2002).

Reports have indicated that several agents or conditions, such as glucocorticoids (Yazawa et al., 2000), radiation (Hasegawa et al., 1997), hydroxyurea (Shin et al., 1999), 1,3-dinitrobenzene (Strandgaard and Miller, 1998), mitomycin C (Nakagawa et al., 1997), heat exposure (Lue et al., 1999, 2000; Rockett et al., 2001), gonadotropin depletion (Sinha Hikim et al., 1995, 1997), FSH and testosterone withdrawal (Tesarik et al., 2002) and cryptorchidism (Plöen, 1973; Shikone et al., 1994), enhance germ cell death. In both spontaneous and injury associated germ cell death, apoptosis appears to occur. 
Early results indicated that efferent duct ligation produced morphological changes in round spermatids, which were similar to apoptotic death but without fragmentation in apoptotic bodies (E. Anton, unpublished).

In the present study the changes produced by efferent duct ligation in round spermatids and multinucleated giant cells were followed by histochemical and ultrastructural methods to determine the participation of the lysosomal enzyme acid phosphatase in the autophagic or heterophagic processes involved in the degradation of dead cells.

\section{Materials and Methods}

Efferent duct ligation was performed unilaterally on Wistar rats of 3-5 months of age weighing 250-300 g that were treated according to 'Guide to the Care and Use of Experimental Animals' by The Canadian Council on Animal Care. The rats were anaesthetized by an i.p. injection of $3.5 \mathrm{mg}$ Embutal $100 \mathrm{~g}^{-1}$ body weight (Abbott Laboratories, Buenos Aires) and both testes were exteriorized through a median suprapubic incision. The efferent ducts of one testis were ligated with 5-0 silk as close as possible to the testis but preserving the integrity of the blood supply. The contralateral, sham-operated testis served as a control. Both testes were returned to the scrotum and the incision was closed by an interrupted suture.

The animals were killed by cervical dislocation on days $1,2,3,5,7$ and 10 after ligation and the testes were removed and perfused with a 27-gauge needle attached to a polyethylene perfusion line. The needle was inserted directly into the spermatic artery at the site where the artery penetrates the tunica albuginea and Tyrode's balanced salt solution (Difco Laboratories, Detroit, MI) containing $0.05 \%(\mathrm{w} / \mathrm{v})$ heparin (Abbott Laboratories, Buenos Aires) was perfused at a rate of $0.21 \mathrm{ml} \mathrm{g}^{-1} \mathrm{~min}^{-1}$ using a Compact Infusion Pump (Sorval Inc., Newtown, CT) until the blood was washed out.

For light microscopy, the described procedure was followed by perfusion of 10-15 ml of Bouin's fixative. Then tissue of $2 \mathrm{~mm}$ thickness for a slide was taken from the middle of the organ and immersed in fresh fixative for $24 \mathrm{~h}$. The slide was embedded in Paraplast Plus (Sigma Chemical Co., St Louis); $2-3 \mu \mathrm{m}$ sections were cut and stained with haematoxylin-eosin, periodic acid-Schiff (PAS) and a modified trichrome technique (Anton, 1999).

The frequency of seminiferous tubules with multinucleated giant cells was obtained by screening at least 150 cross-sectioned tubules.

Apoptotic cells were identified by the modified trichrome technique that stains apoptotic nuclei and apoptotic bodies red in contrast to normal nuclei, which are stained green (Anton, 1999).

The frequency of tubules containing at least one apoptotic nucleus was scored in 450 tubules of control rats and in 150 tubules at each time after efferent duct ligation.

For electron microscopic observations, fixation involved perfusion of $5 \%(\mathrm{v} / \mathrm{v})$ glutaraldehyde (Fluka Chemie AG, Buchs) in 0.1 mol cacodylate $\mathrm{I}^{-1}$ buffer, $\mathrm{pH} 7.4$, for 15 min into the spermatic artery. The testes were then cut into slices of $1 \mathrm{~mm}$ thickness and the slices were immersed in fresh fixative for $2 \mathrm{~h}$ and washed overnight in the same buffer containing $0.25 \mathrm{~mol}$ sucrose $\mathrm{I}^{-1}$.

For conventional electron microscopy, blocks of $1 \mathrm{~mm}^{3}$ were cut, postfixed in $1 \%(\mathrm{w} / \mathrm{v})$ osmium tetroxide (Fluka) in cacodylate buffer, $\mathrm{pH} \mathrm{7.4,} \mathrm{and} \mathrm{embedded} \mathrm{in}$ epoxy resin Epon 812 (Fischer Scientific Co., Fair Lawn, NJ) or Maraglas 655 (Polysciences Inc., Warrington, PA).

For histochemical studies of acid phosphatase, a block of tissue $1 \mathrm{~mm} \times 2 \mathrm{~mm} \times 2 \mathrm{~mm}$ was embedded in $7 \%(\mathrm{w} / \mathrm{v})$ agar (Difco) and cut at 40-60 $\mu \mathrm{m}$ with a Sorvall tissue chopper (Smith Farquhar tissue sectioner). Sections were incubated for $60 \mathrm{~min}$ at $37^{\circ} \mathrm{C}$ at pH 5.0 in a Gomori's lead salt medium (Gomori, 1952) containing $\beta$-glycerophosphate grade I (Sigma) as substrate, postfixed in $2 \%$ osmium tetroxide and $3 \%(\mathrm{w} / \mathrm{v})$ potassium ferrocyanide (Mallinckrodt Chemical Works, New York) and embedded flat in Epon or Maraglas.

Sections incubated in the same medium that also contained 0.01 mol sodium fluoride $\mathrm{I}^{-1}$ were used as controls for the acid phosphatase technique as well as medium lacking the substrate.

For conventional and histochemical observations, ultrathin sections were cut with a Porter Blum microtome and the grids were first examined without staining to avoid obscuring the lead phosphate reaction precipitate, and eventually counterstained lightly with uranyl acetate followed by lead citrate. Electron micrographs were taken with a Zeiss EM-9 or Siemens Elmiskop I electron microscope.

The contralateral sham-operated testis and normal testis from untreated animals were used as controls and were processed in the same way as the operated testes.

\section{Results}

\section{Light microscopy}

Control testes. Throughout the experiment, the histology of the sham-operated testes was undistinguishable from that of normal untreated rats of the same age. All the stages of the cycle of the seminiferous epithelium were present and the rate of spontaneous apoptotic cells was very low. The trichrome stain demonstrated that this rate was very low as only $4 \%$ of the tubes showed one or more apoptotic nuclei. Red nuclei always appeared near the basal lamina and displayed the characteristics of spontaneous degeneration (Fig. 1a). Multinucleated giant cells were never seen. 

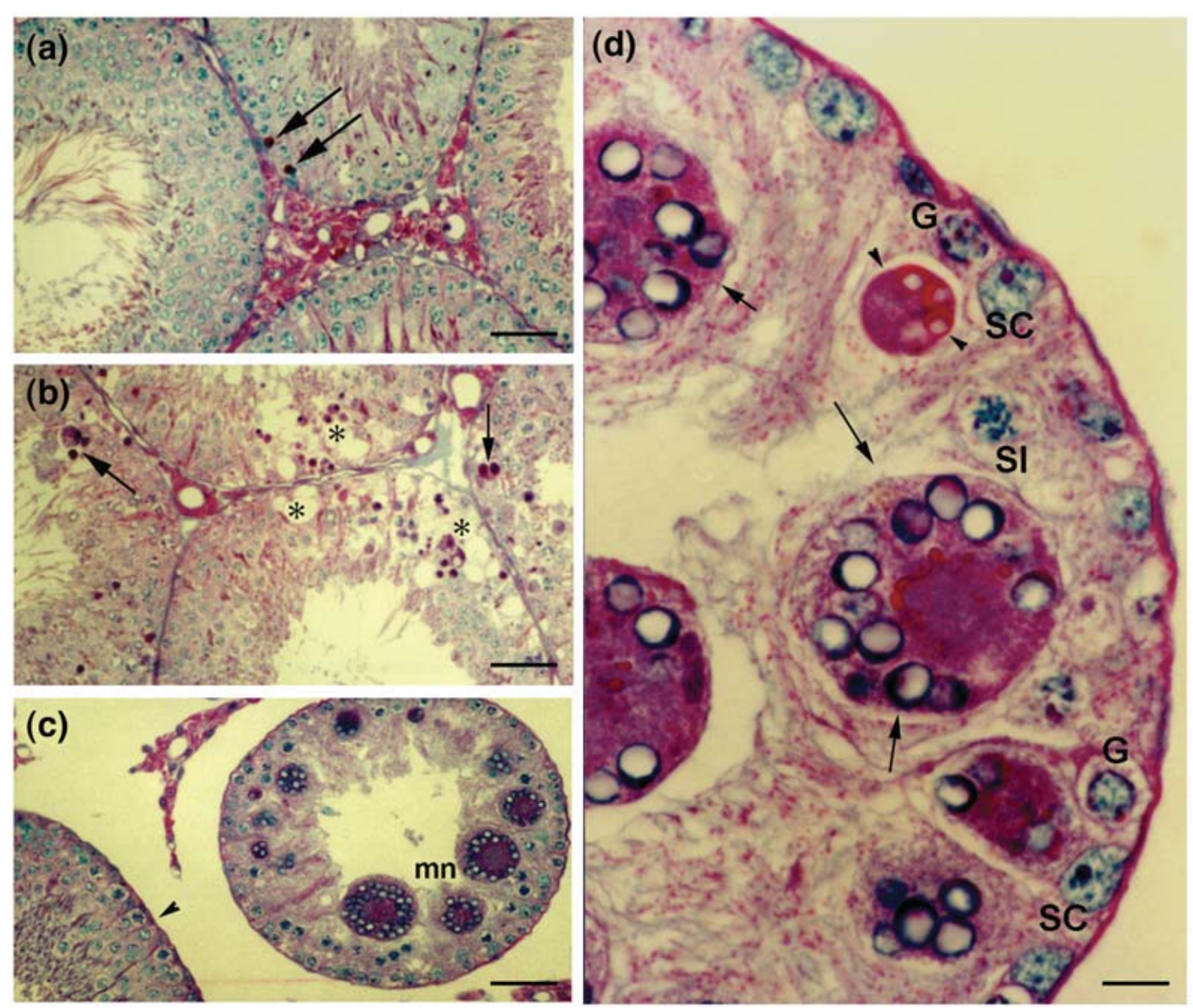

Fig. 1. Rat testes stained with the modified trichrome technique. (a) In the untreated control very few apoptotic cells (arrows), which are always localized near the basal part of the seminiferous tubules, are observed. (b) At day 2 after efferent duct ligation numerous apoptotic cells (arrows) appear and Sertoli cells show a marked vacuolization (asterisks). (c) At day 7 after efferent duct ligation most tubules show a reduction in the tubular diameter and various degrees of degeneration. Only a few apparently normal tubules remain (arrowhead); multinucleated giant cells $(\mathrm{mn})$ displaying annular condensation of the chromatin are frequently seen. (d) At day 7 after efferent duct ligation a seminiferous tubule at high magnification showing two types of multinucleated giant cells: larger cells (arrows) present many peripheral nuclei, annular chromatin staining green-bluish, and in the cytoplasm red granules; smaller multinucleated cells (arrowheads) present few nuclei with bright red annular chromatin. SC: Sertoli cells; G: spermatogonia; SI: primary spermatocyte. Scale bars represent $(a, b, c) 50 \mu \mathrm{m}$ and (d) $10 \mu \mathrm{m}$.

Day 2 after efferent duct ligation. Exfoliated round spermatids and spermatocytes appeared in the tubular lumen, and $8 \%$ of the tubules presented multinucleated giant cells. The chromatin was condensed against the nuclear membrane in some of the immature spermatids, and highly vacuolized Sertoli cells could be seen in some of the tubules (Fig. 1b). Moreover, up to $24 \%$ of the tubules presented cells with the characteristic red coloration of apoptotic nuclei (Fig. 1b).

Days 5 and 7 after efferent duct ligation. The alterations observed on days 5 and 7 after efferent duct ligation were alike, but damage became much greater with time (Fig. 1c,d). Thus, the percentage of tubules containing multinucleated giant cells significantly increased from $47 \%$ on day 5 after efferent duct ligation to $65 \%$ on day 7 after efferent duct ligation, while the frequency of tubules with apoptotic stain remained about the same ( $77 \%$ on day 5 and $84 \%$ on day 7 ).

Injured tubules presented no mature spermatids but always contained Sertoli cells, spermatogonia, and few primary spermatocytes.

Some tubules showed a striking accumulation of multinucleated giant cells, whereas in others few or 


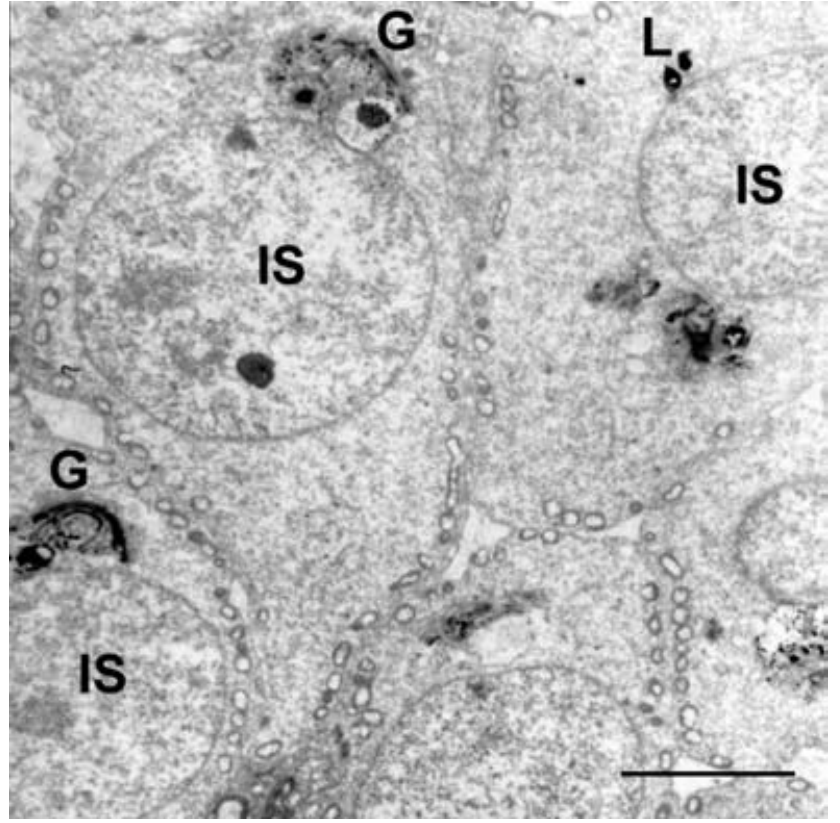

Fig. 2. Electron micrograph of acid phosphatase reaction in testis of normal control rat. The section is stained with uranyl acetate and lead citrate. A group of normal immature round spermatids (IS) is shown; the nuclei present decondensed chromatin and a large Golgi apparatus (G) with intense acid phosphatase-positive reaction in cisternae, granules and the acrosome. Very few lysosomes are seen (L). Scale bar represents $2.5 \mu \mathrm{m}$.

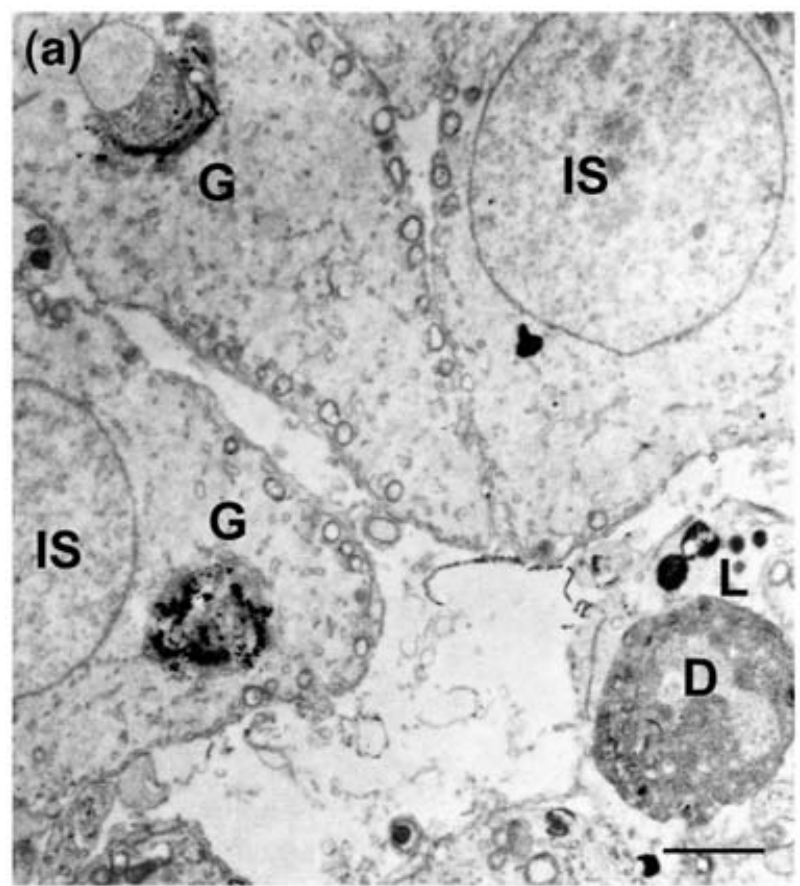

none were observed. Multinucleated giant cells always appeared in the lumen of the tubules and seemed to be detached from the epithelium. Their nuclei were arranged along the periphery of the cells and the cytoplasm, which stained slightly with PAS, showed red granules of different sizes with the trichrome stain (Fig. 1d).

The nuclei of small multinucleated giant cells were small and stained brightly red with the trichrome stain; in contrast, in the nuclei of large multinucleated giant cells, the chromatin was condensed against the nuclear membrane, and stained green at the periphery while the centre failed to stain with either haematoxylin-eosin, PAS or trichrome stain. A proportion (three large:one small) of giant cells was usually observed.

Some tubules did not show multinucleated giant cells but presented many free round spermatids. The nuclei of these cells showed red stain with very similar characteristics to the nuclei of small multinucleated giant cells.

In spite of the severe epithelial degeneration displayed by most of the tubules, a few rather well preserved tubules could still be seen next to those which were abnormal.

\section{Histochemistry}

Control testes. Acid phosphatase was observed in the lysosomes of Sertoli cells and in cisternae of

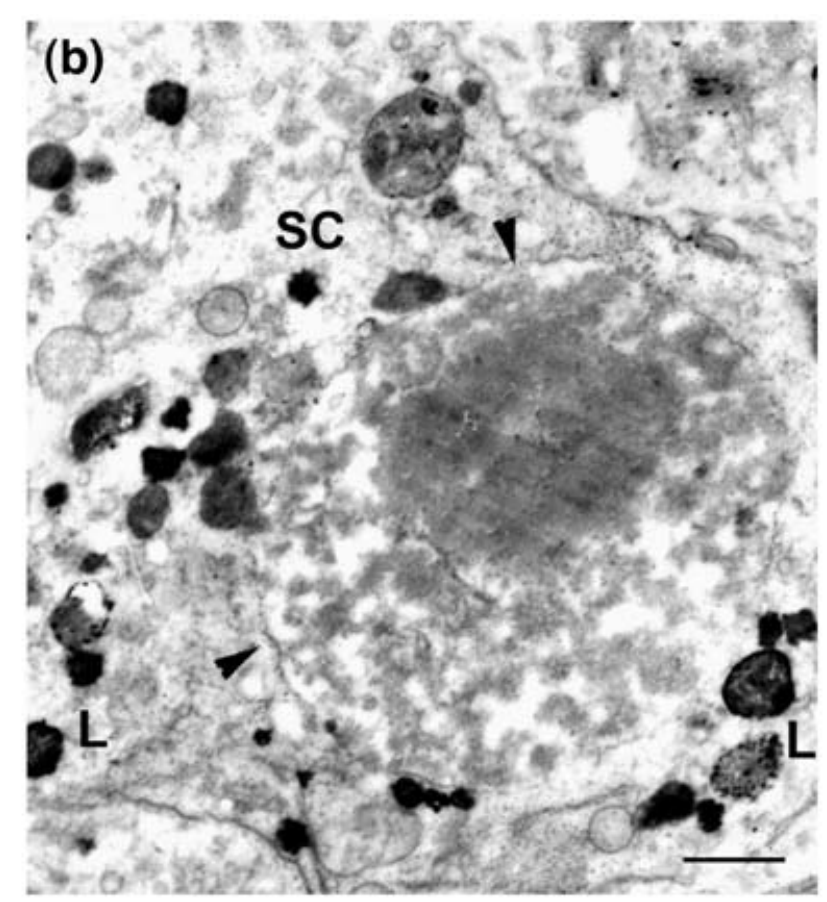

Fig. 3. Electron micrographs of acid phosphatase reaction in rat testes on day 1 after efferent duct ligation. Sections are without further stain. (a) In the luminal area of a seminiferous tubule round spermatids (IS) show normal chromatin structure and prominent Golgi complexes $(\mathrm{G})$ with intense acid phosphatase reaction in cisternae and granules. A degenerate cell (D) with lysosomes (L) nearby is seen at the lower right corner. (b) In the basal area of a seminiferous tubule the cytoplasm of a Sertoli cell (SC) shows many lysosomes (L) with acid phosphatase-positive reaction surrounding a necrotic phagocytozed cell (arrowheads). Scale bars represent (a) $2.5 \mu \mathrm{m}$ and (b) $1.0 \mu \mathrm{m}$. 


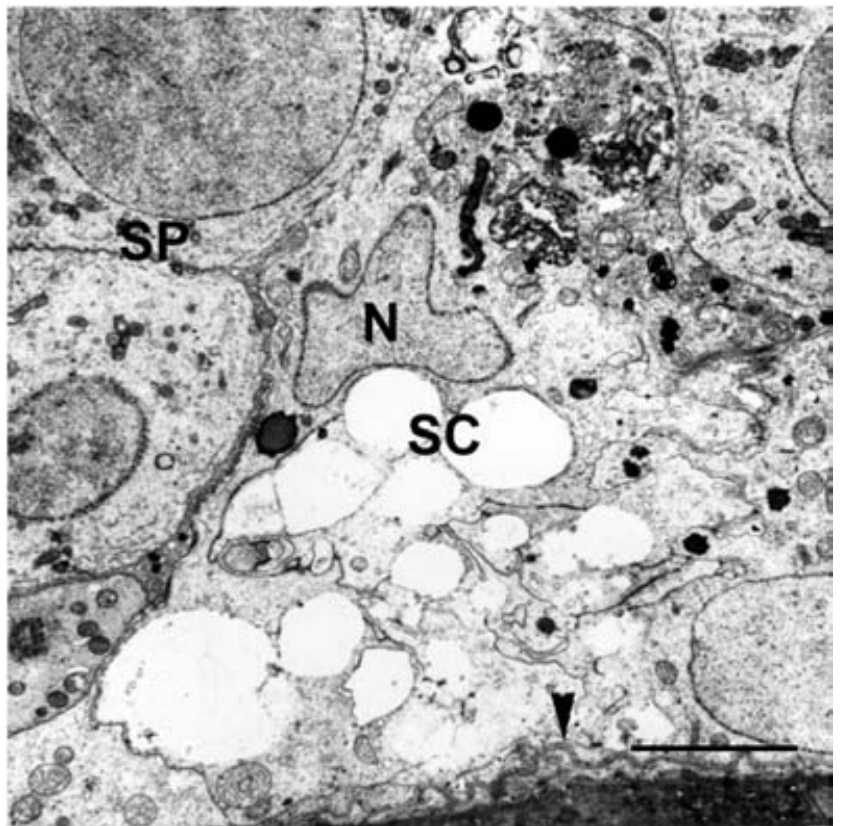

Fig. 4. Electron micrograph of acid phosphatase reaction in rat testis on day 3 after efferent duct ligation. The section is stained with uranyl acetate and lead citrate. In the basal part of a seminiferous tubule the cytoplasm of a Sertoli cell (SC) contains many large clear empty vacuoles; the nucleus $(\mathrm{N})$ and organelles are brought close together in the upper cytoplasm. Parts of normal primary spermatocytes (SP) are also observed. The basal laminae (arrowhead) shows an abnormal undulation. Scale bar represents $5 \mu \mathrm{m}$.

the Golgi complex of spermatogonia and spermatocytes. The largest Golgi complex was seen in round spermatids undergoing acrosome formation. Very few small lysosomes with a positive acid phosphatase reaction and some lipid droplets were observed in the cytoplasm of immature spermatids (Fig. 2) and in residual bodies.

Day 1 after efferent duct ligation. Round spermatids maintained their normal structure and presented a similar reaction to that observed in the Golgi complex of normal rats (Fig. 3a). Engulfment of dead cells by the Sertoli cells provided evidence of heterophagy, and a strong acid phosphatase reaction could be seen in the lysosomes surrounding the phagocytic vacuoles (Fig. 3b). Thus, normal phagocytic and lysosomal activities were still maintained on day 1 after efferent duct ligation.

Day 3 after efferent duct ligation. Many round spermatids presented clear chromatin at the centre of the nucleus and a zone of much denser chromatin associated with the nuclear membrane. Although some round spermatids showed a normal Golgi complex with acid phosphatase reaction, in others there was evidence of abnormal acrosome formation with accumulation of granules. Lysosomes were seldom observed in round spermatids

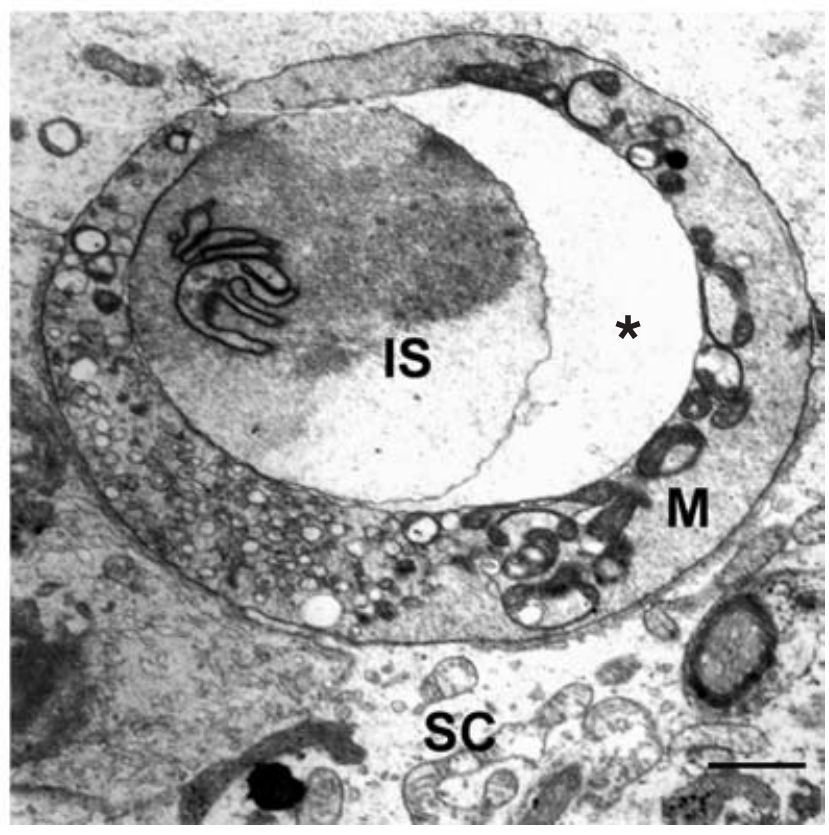

Fig. 5. Electron micrograph of acid phosphatase reaction technique in rat testis on day 5 after efferent duct ligation. The section is stained with uranyl acetate and lead citrate. An apoptotic round spermatid (IS) presenting chromatin condensation and membranous inclusions in the nucleus is seen. In some parts, the space between the two nuclear membranes is abnormally wide (asterisk). Dark and elongated mitochondria (M) enclose parts of the cytoplasm, which also contains many small vesicles. The spermatid is in contact with the cytoplasm of a Sertoli cell (SC) but no lysosomes appear near the apoptotic cell. Scale bar represents $2 \mu \mathrm{m}$.

but chromatoid bodies and lipid droplets were frequently seen.

Severe cytoplasmic vacuolization was observed in the basal cytoplasm of Sertoli cells, and some tubules showed very large vacuoles whereas others presented multiple small vesicles (Fig. 4).

A few multinucleated giant cells could be seen in the lumen of some tubules and their clear nuclear characteristics were similar to those of abnormal isolated round spermatids. Cellular debris was frequently observed in the space between abnormal spermatids.

Days 5, 7 and 10 after efferent duct ligation. A characteristic apoptotic feature appeared in most round spermatids: a ring of chromatin condensation against the nuclear envelope. Some of these cells also presented a wide separation between the two nuclear membranes but the inner membrane remained close to the nuclear matrix (Fig. 5).

Abnormal formation of the acrosome caused deep indentations in the nuclei of round spermatids, and it seems probable that many of the membranous structures observed in nuclei of altered spermatids were in fact 

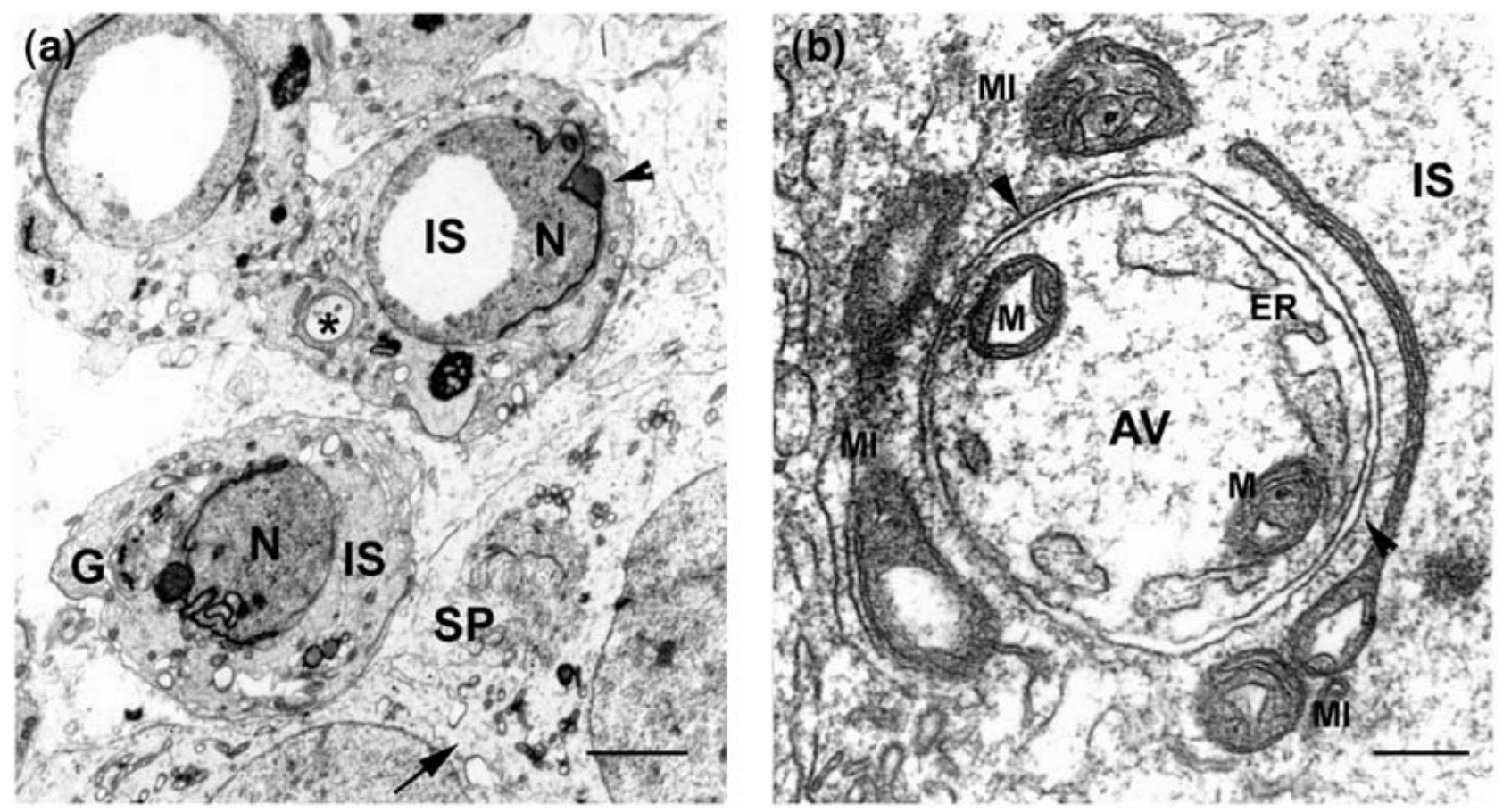

Fig. 6. Electron micrographs of acid phosphatase reaction in rat testes on day 7 after efferent duct ligation. Sections are stained with uranyl acetate and lead citrate. (a) The luminal area of a seminiferous tubule shows a group of round spermatids (IS) with severe nuclear and cytoplasmic alterations. The nuclei present annular condensation of the chromatin ( $\mathrm{N}$ ) and membranous inclusions. Abnormal acrosomes (arrowhead), Golgi cisternae (G) with acid phosphatase reaction, and autophagic vacuoles are seen in the cytoplasm (asterisk). Two normal primary spermatocytes (SP) still connected by a cytoplasmic bridge (arrow) are shown. (b) The cytoplasm of a round spermatid (IS) shows a typical autophagic vacuole (AV) enclosed by a double membrane (arrowheads) and containing mitochondria (M) and endoplasmic reticulum (ER); on the outside, a group of mitochondria (MI) partially encircles the autophagic vacuole but lysosomes are not observed. Scale bars represent (a) $2.5 \mu \mathrm{m}$ and (b) $0.25 \mu \mathrm{m}$.

acrosome protrusions. No sign of nuclear or cytoplasmic protrusion (blebs) formation was found (Fig. 6a).

Autophagic vacuoles were frequently seen in round spermatids and in multinucleated giant cells. Some organelles appeared to be separated from the rest of the cytoplasm by single or double membranes; moreover, narrow dark mitochondria enclosed portions of the cytoplasm but no lyososomes or acid phosphatasepositive bodies associated with them (Fig. 6b).

Multinucleated giant cells were frequently observed in the lumen of seminiferous tubules after efferent duct ligation. As seen with light microscopy two different types or, perhaps, two different stages in the advance of the degradative process were present among them. Most of the multinucleated giant cells appeared to correspond to the type that was described, by light microscopy, as displaying a green peripheral nuclear stain when observed with the trichrome procedure (Fig. 1d). These cells were large and contained multiple nuclei, which were similar to those of isolated altered round spermatids. The nuclei presented the annular chromatin condensation characteristic of apoptosis and numerous membranous inclusions (Fig. 7a). The cytoplasm showed vacuoles of different size, autophagic vacuoles, and slender dark mi- tochondria that surrounded vesicular structures. Whether the organelles could be recognized depended on the stage of the degradative process. Neither lysosomes nor acid phosphatase-positive structures were observed (Fig. 7a).

The second type of multinucleated giant cell was smaller and contained fewer nuclei than the first type. In these cells, the chromatin was completely compacted; the two layers of the nuclear envelope were widely separated, and many clear vacuoles occupied most of the cytoplasm (Fig. 7b).

Although abnormal round spermatids and both types of multinucleated giant cell were frequently surrounded by the cytoplasm of Sertoli cells (Fig. 7a,b), no lysosomes or signs of phagocytosis were observed.

\section{Discussion}

Disruption of the normal organization of chromatin is a central feature of apoptosis and serves as the most characteristic morphological criterion for identification of this type of cell death (Kerr et al., 1972; Walker et al., 1988; Dini et al., 1996). Programmed cell death 

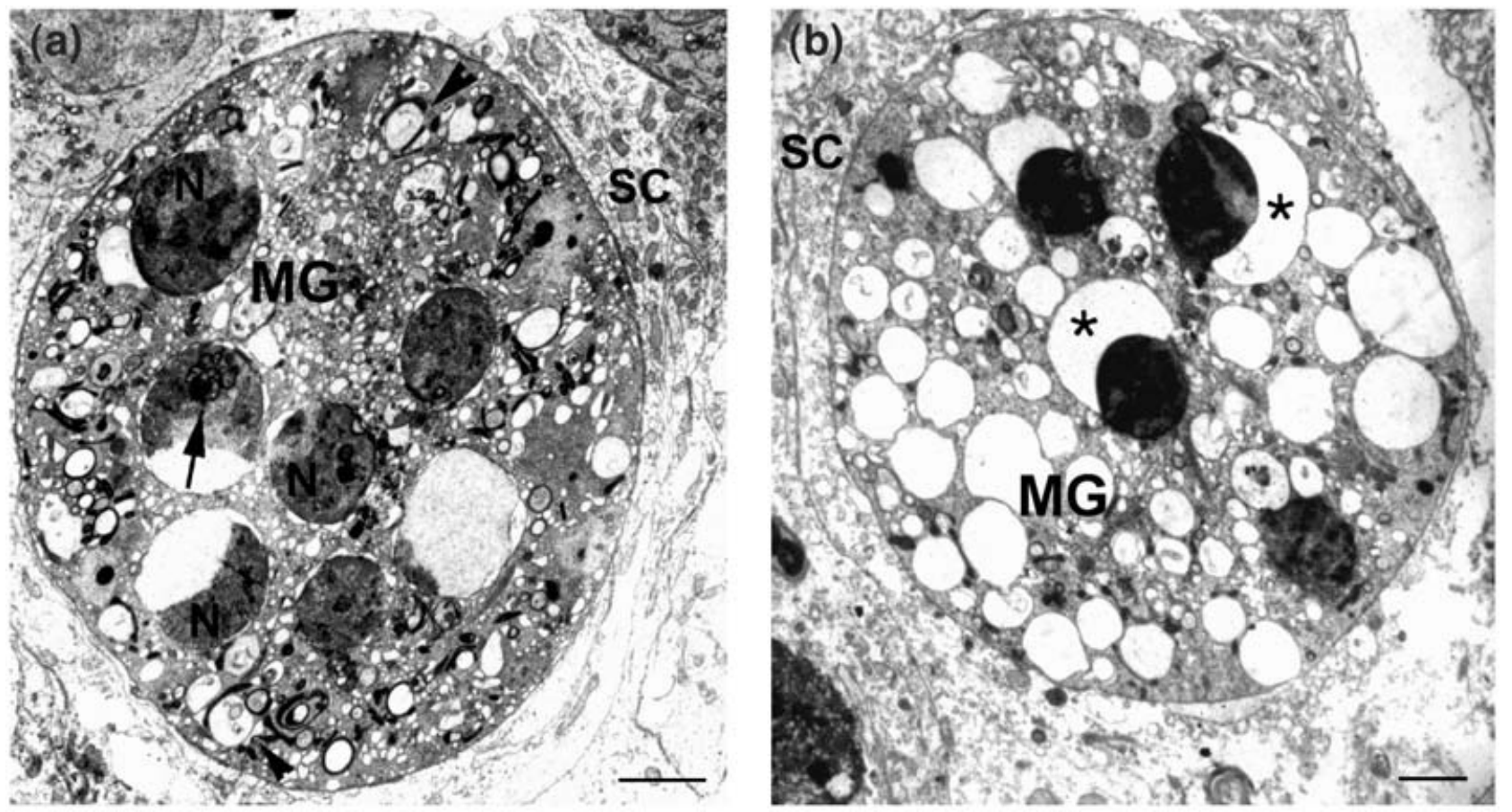

Fig. 7. Electron micrographs of acid phosphatase reaction in rat testes on day 10 after efferent duct ligation. Sections are stained with uranyl acetate and lead citrate. (a) A multinucleated giant cell (MG) shows condensed chromatin and membranous inclusions (arrow) in the nuclei (N). The cytoplasm contains slender mitochondria encircling vacuolar structures (arrowheads). The cytoplasm of the Sertoli cell (SC) lacks lysosomal structures. (b) Multinucleated giant cell (MG) showing fewer nuclei than that in (a). The chromatin is fully condensed, and large clear areas (asterisks) produced by separation of the nuclear membranes are seen. The cytoplasm is occupied by several vesicles but few organoids appear. The cytoplasm of the Sertoli cell (SC), like that in (a), lacks lysosomal structures. Scale bars represent $2.5 \mu \mathrm{m}$.

is not limited to apoptosis; autophagy too is a pathway for active self-destruction. Apoptasis and autophagy are not mutually exclusive and dying cells can display both apoptotic and autophagic features (Bursch, 2001).

Although testicular fluid blockage caused a rapid apoptotic response in immature spermatids as demonstrated in the present investigation, the process did not progress and the cells developed apoptotic nuclear morphology with condensation and margination of chromatin but without nuclear fragmentation or formation of apoptotic bodies. Furthermore, even on day 10 after efferent duct ligation, there were no signs of phagocytosis by neighbouring Sertoli cells; lysosomes were absent; and no hydrolytic activity was detected in the autophagic vacuoles observed. Similar changes were observed in the numerous multinucleated giant cells that appeared after ligation.

The presence of multinucleated giant cells was similar to that observed in other procedures that disturb spermatogenesis and appears to represent a non-specific reaction to injury (Plöen, 1973; Sakamoto et al., 1988; Strandgaard and Miller, 1998). Thus, ligation resulted in arrested apoptosis and also in abortive autophagic and heterophagic responses because neither the autophagic vacuoles formed in the apoptotic cells nor the Sertoli cells that surrounded those cells advanced in the degradative process.

In normal testes, disposal of residual bodies and dead cells appears to be a phagocytic function of Sertoli cells after a previous degradation step started by autophagy (Dieter, 1966; Chemes, 1986). Heterophagy would also be required since acid phosphatase activity has been detected only in Sertoli cells when the residual bodies phagocytozed by those cells already presented signs of disintegration owing to fusion with acid phosphatasepositive lysosomes (Morales et al., 1985). Moreover, the segregation of portions of cytoplasm by endoplasmic reticulum, mitochondria (Webster, 1962; Anton, 1991) or Golgi membranes (Ericsson, 1969) is a well known step in the formation of autophagic vacuoles both in functional and pathological conditions, and autophagic vacuoles are an active defence mechanism allowing cytoplasmic organelles to be sequestered and digested (degraded) by action of lysosomal enzymes (Ericsson, 1969). However, autophagy appears to be a tightly controlled cytoplasmic event that does not bring about apoptosis, because when the nucleus remains relatively well preserved, staining by TdT-mediated dUTP nick-end labelling (TUNEL) is negative (Bursch, 2001). Although autophagic vacuoles and sequestering of cytoplasmic organelles were observed, lysosomes and acid phosphatase reaction 
were absent in the apoptotic cells caused by efferent duct ligation as if the mechanisms for identification and disposal of damage were not functioning properly.

An important step in apoptosis is the formation and release of apoptotic bodies that are recognized and engulfed by neighbouring cells (Walker et al., 1988). The formation of apoptotic bodies is a multistaged process regulated differentially by $\mathrm{Bcl}-2$ and caspases. Bcl-2 prevents most of the manifestations of apoptosis at the ultrastructural level and stops formation of apoptotic bodies, whereas caspase inhibitors produce partial condensation of chromatin and lead to the appearance of multiple cytoplasmic vesicles (Zhang et al., 1999). Although caspase activation followed by DNA fragmentation are well known steps when apoptosis develops in most of the tissues, testicular germ cells showed a different pattern after FSH and testosterone withdrawal in tissue culture, Thus, DNA fragmentation occurred in primary spermatocytes and spermatids but was not accompanied by caspase activity (Tesarik et al., 2002).

Membrane unpacking of apoptotic cells and bodies is essential for recognition and clearance by phagocytic cells. Macrophages can detect changes resulting in exposure of phosphatidyserine on the external side of the cell membrane. This phospholipid interacts selectively with a specific receptor on the surface of the macrophage (Fadok et al., 2000) eliciting phagocytosis of apoptotic cells and bodies (Fadok et al., 1992). Lack of phagocytosis after efferent duct ligation could be due to inability of the Sertoli cells to recognize those alterations in the membrane of apoptotic-necrotic cells or perhaps to the absence of changes in the membrane of germ cells (Messmer and Pfeilschifter, 2000). Evidence of the absence of externalization of phosphatidyserine in round spermatids (Tesarik et al., 1998) indicates that the second possibility is the most probable cause of the lack of phagocytosis. In fact, testicular apoptosis has quite different characteristics from those displayed by somatic cells (Brinkworth et al., 1995).

At least some of the effects of efferent duct ligation could be assigned to alterations in the interplay between regulatory factors controlling the different steps in the apoptotic process. Further studies are needed to determine whether apoptosis did not reach completion due to failure of the cellular mechanisms controlling autophagy and heterophagy, or whether the absence of autophagy and heterophagy resulted from the inability of apoptosis to progress to the stage that evokes the degradative response.

E. Anton is Career Investigator of the Consejo Nacional de Investigaciones Científicas y Técnicas.

\section{References}

Anton E (1979) Early ultrastructural changes in the rat testis after ductuli efferentes ligation Fertility and Sterility 31 187-194
Anton E (1991) Involvement of mitochondria in degradative processes evoked by ductuli efferentes ligation in rats Comunicaciones Biológicas 9 243-248

Anton E (1999) Detection of apoptosis by a modified trichrome technique Journal of Histotechnology 22 301-304

Brinkworth MH, Weinbauer GF, Schlatt S and Nieschlag E (1995) Identification of male germ cells undergoing apoptosis in adult rats Journal of Reproduction and Fertility 105 25-33

Bursch W (2001) The autophagosomal-lysosomal compartment in programmed cell death Cell Death and Differentiation 8 569-581

Chemes H (1986) The phagocytic function of Sertoli cells: a morphological, biochemical, and endocrinological study of lysosomes and acid phosphatase localization in the rat testis Endocrinology 1191673 1681

De Rooij DG and Lok D (1987) Regulation of the density of spermatogonia in the seminiferous epithelium of the chinese hamster: II Differentiating spermatogonia Anatomical Record 217 131-136

Dieter SE (1966) Fine structure of the formation and fate of the residual bodies of mouse spermatozoa with evidence of the participation of lysosomes Journal of Morphology 120 317-346

Dini L, Coppola S, Ruzittu MT and Ghibelli L (1996) Multiple pathways for apoptotic nuclear fragmentation Experimental Cell Research 223 340347

Ericsson JLE (1969) Mechanism of cellular autophagy. In Lysosomes in Biology and Pathology pp 345-393 Eds JT Dingle and HB Fell. NorthHolland Publishing Company, Amsterdam

Fadok VA, Voelker DR, Campbell PA, Cohen JJ, Bratton DL and Henson PM (1992) Exposure of phosphatidylserine on the surface of apoptotic lymphocytes triggers specific recognition and removal by macrophages Journal of Immunology 148 2207-2216

Fadok VA, Bratton DL, Rose DM, Pearson A, Ezekewitz RAB and Henson PM (2000) A receptor for phosphatidylserine-specific clearance of apoptotic cells Nature $\mathbf{4 0 5} 85-90$

Gomori G (1952) In Microscopic Histochemistry. Principles and Practice pp 189-194 University of Chicago Press, Chicago, IL

Hasegawa M, Wilson G, Russell LD and Meistrich ML (1997) Radiationinduced cell death in the mouse testis: relationship to apoptosis Radiation Research 147 457-467

Kerr JFR, Wyllie AH and Currie AR (1972) Apoptosis: a basic biological phenomenon with wide-ranging implications in tissue kinetics British Journal of Cancer 26 239-257

Kitanaka C and Kuchino Y (1999) Caspase-independent programmed cell death with necrotic morphology Cell Death and Differentiation 6 508515

Lue YH, Sinha Hikim AP, Swerdloff RS, Im P, Taing KS, Bui T, Leung A and Wang C (1999) Single exposure to heat induces stage-specific germ cell apoptosis in rats: role of intratesticular testosterone on stage specificity Endocrinology 140 1709-1717

Lue YH, Sinha Hikim AP, Wang C Im, M, Leung A and Swerdloff RS (2000) Testicular heat exposure enhances the suppression of spermatogenesis by testosterone in rats: The "two-hit" approach to male contraceptive development Endocrinology 141 1414-1424

Majno G and Joris I (1995) Apoptosis, oncosis, and necrosis: an overview of cell death American Journal of Pathology 146 3-15

Matsui Y (1998) Regulation of germ cell death in mammalian gonads Acta Pathologica, Microbiologica et Immunologica Scandinavica 106142 148

Messmer UK and Pfeilschifter J (2000) New insights into the mechanism for clearance of apoptotic cells BioEssays 22 878-881

Morales C, Clermont $\mathbf{Y}$ and Hermo L (1985) Nature and function of endocytosis in Sertoli cells of the rat American Journal of Anatomy $\mathbf{1 7 3}$ 203-217

Nakagawa S, Nakamura N, Fujioka M and Mori C (1997) Spermatogenic cell apoptosis induced by Mitomycin $\mathrm{C}$ in the mouse testis Toxicology and Applied Pharmacology 147 204-213

Plöen L (1973) A light microscopic study of the immediate and delayed effects on rabbit spermatogenesis following experimental cryptorchidism for twenty-four hours Virchows Archiv Abteilung B. Zellpathologie 14 185-196 
Rockett JC, Mapp FL, Garges JB, Luft JC, Mori C and Dix DJ (2001) Effects of hyperthermia on spermatogenesis, apoptosis, gene expression, and fertility in adult male mice Biology of Reproduction 65 229-239

Sakai Y and Yamashina S (1989) Mechanism for the removal of residual cytoplasm from spermatids during mouse spermiogenesis Anatomical Record 223 43-48

Sakamoto J, Kurosaka Y and Hashimoto K (1988) Histological changes of acrylamide-induced testicular lesions in mice Experimental and Molecular Pathology 48 324-334

Sakkas D, Mariethoz E and St John JC (1999) Abnormal sperm parameters in human are indicative of an abortive apoptotic mechanism linked to the Fas-mediated pathway Experimental Cell Research 251 350-355

Shikone T, Billig H and Hsueh AJW (1994) Experimentally induced cryptorchidism increases apoptosis in rat testis Biology of Reproduction $51865-872$

Shin J-H, Mori C and Shiota K (1999) Involvement of germ cell apoptosis in the induction of testicular toxicity following hydroxyurea treatment Toxicology and Applied Pharmacology 155 139-149

Singh SK and Abe K (1987) Light and electron microscopic observations of giant cells in the mouse testis after efferent duct ligation Archivum Histologicum Japonicum 50 579-585

Sinha Hikim AP, Wang C, Leung A and Swerdloff RS (1995) Involvement of apoptosis in the induction of germ cell degeneration in adult rats after gonadotropin-releasing hormone antagonist treatment Endocrinology $1362770-2775$

Sinha Hikim AP, Rajavashisth TB, Sinha Hikim I, Lue Y, Bonavera JJ, Leung A, Wang C and Swerdloff RS (1997) Significance of apoptosis in the temporal and stage-specific loss of germ cells in the adult rat after gonadotropin deprivation Biology of Reproduction 57 1193-1201

Smith G (1962) The effects of ligation of the vasa efferentia and vasectomy on testicular function in the adult rat Journal of Endocrinology 23 385-399

Strandgaard C and Miller MG (1998) Germ cell apoptosis in rat testis after administration of 1,3-dinitrobenzene Reproductive Toxicology 12 97103
Tao L, Zupp JL and Setchell BP (2000) Effect of efferent duct ligation on the function of the blood-testis barrier in rats Journal of Reproduction and Fertility 120 13-18

Tesarik J, Greco E, Cohen-Bacrie P and Mendoza C (1998) Germ cell apoptosis in men with complete and incomplete spermatogenesis failure Molecular Human Reproduction 4 757-762

Tesarik J, Martinez F, Rienzi L, lacobelli M, Ubaldi F, Mendoza C and Greco E (2002) In-vitro effects of FSH and testosterone withdrawal on caspase activation and DNA fragmentation in different cell types of human seminiferous epithelium Human Reproduction 17 1811-1819

Vanha-Perttula T and Arya M (1985) Lectin staining of rat testis and epididymis after ligation of excurrent ducts at different levels Biology of Reproduction 33 477-485

Walker NI, Harmon BV, Gobé, GC and Kerr JFR (1988) Patterns of cell death. In Methods and Achievements in Experimental Pathology Vol. 13 pp 18-54 Ed. G Jasmin. Karger, Basel

Webster H de F (1962) Transient, focal accumulation of axonal mitochondria during the early stages of Wallerian degeneration Journal of Cell Biology 12 361-383

Weil M, Jacobson MD and Raff MC (1998) Are caspaes involved in the death of cells with a transcriptionally inactive nucleus? Sperm and chicken erythrocytes Journal of Cell Sciences 111 2707-2715

Yazawa H, Sasagawa I and Nakada T (2000) Apoptosis of testicular germ cells induced by exogenous glucocorticoid in rats Human Reproduction 15 1917-1920

Zhang J, Reedy MC, Hannun YA and Obeid LM (1999) Inhibition of caspases inhibits the release of apoptotic bodies: $\mathrm{Bcl}-2$ inhibits the initiation of formation of apoptotic bodies in chemotherapeutic agent-induced apoptosis Journal of Cell Biology 145 99-108

Received 11 October 2002

First decision 5 December 2002.

Revised manuscript received 14 February 2003.

Accepted 20 February 2003. 